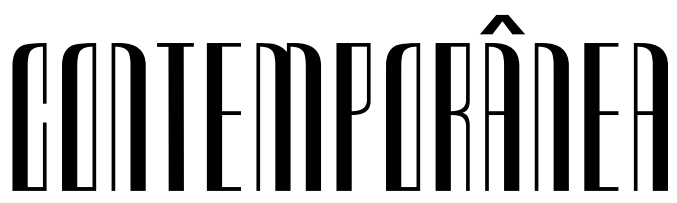

hitps://doi.org/10.4322/2316-1329.2021003

Contemporânea

Dossiê Sociologias da Deficiência

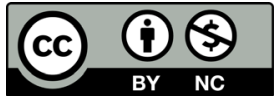

v. 11 , n. 2 p. $506-540$

Maio-Ago. 2021

Esta obra está licenciada com uma Licença Creative Commons Atribuição-NãoComercial 4.0 Internacional.

\section{Vida Independente para Pessoas com Deficiência: do individualismo à autodeterminação}

\author{
Fernando Fontes ${ }^{1}$ \\ Bruno Sena Martins ${ }^{2}$
}

Resumo: O Movimento pela Vida Independente para Pessoas com Deficiência tem ao longo das últimas quase cinco décadas reconfigurado as políticas sociais na área da deficiência em diferentes países do mundo ocidental. Neste movimento conjugam-se, sem contradição, alguns dos valores que estruturam o individualismo moderno e as concepções liberais de autonomia e da responsabilidade individual. Este artigo faz uma arqueologia deste movimento, de forma a situarmos a reivindicação por uma Vida Independente nas agendas do presente das organizações e do movimento de pessoas com deficiência, e de forma a refletir sobre o modo como a Vida Independente para pessoas com deficiência integra e articula alguns dos valores e concepções dominantes nas sociedades capitalistas ocidentais.

Palavras-chave: Deficiência; Vida Independente; Autodeterminação; Capacitismo; Portugal.

\section{Independent Living for Disabled People: from individualism to self-determination}

Abstract: The Independent Living Movement for Disabled has over the past five decades reconfigured social policies in the area of disability in different countries of the Western world. This movement combines, without contradiction, some of the values that structure modern individualism and liberal conceptions of autonomy and individual responsibility. This article makes an archaeology of this movement, in order, to situate the demand for Independent Living in the present agendas of the organizations of disabled people and of the Disabled People's Movement. Hence, it reflects on how Independent Living for disabled people integrates and articulates values and conceptions dominant in western capitalist societies.

Keywords: Disability; Independent Living; Self-determination; Ableism; Portugal.

\section{Vida independiente para personas con discapacidad: del individualismo a la autodeterminación}

Resumen: El Movimiento de Vida Independiente para Personas con Discapacidad /Diversidad Funcional en las últimas cinco décadas ha reconfigurado las políticas sociales en el área en diferentes países del mundo occidental. Este movimiento combina, sin contradicción, algunos de los valores que estructuran el individualismo moderno y las concepciones liberales de autonomía y responsabilidad individual. Este artículo hace una arqueología de este movimiento, con el fin de situar la demanda de Vida Independiente en las agendas actuales de las

1 Centro de Estudos Sociais da Universidade de Coimbra (CES/UC) - Coimbra - Portugal - fer.fontes@gmail.com - ORCID: 0000-0001-8792-262X

2 Centro de Estudos Sociais da Universidade de Coimbra (CES/UC) - Coimbra - Portugal - bsenamartins@gmail.com - ORCID: 0000-0003-3367-9155 
organizaciones de personas con discapacidad y del Movimiento de Personas con Discapacidad. Por lo tanto, reflexiona sobre cómo la vida independiente para personas con discapacidad integra y articula los valores y concepciones dominantes en las sociedades capitalistas occidentales.

Palabras clave: Discapacidad; Vida independiente; Autodeterminación; Capacitismo; Portugal.

\section{INTRODUÇÃO}

O Movimento pela Vida Independente para Pessoas com Deficiência surge nos Estados Unidos da América (EUA) no final da década de 1960, tendo o primeiro Centro de Vida Independente sido criado em Berkeley em 1972 (Djong, 1979). Na Europa, não obstante a emergência de grupos organizados de pessoas com deficiência a partir da década de 1970, maioritariamente ex-residentes de unidades residenciais em busca de soluções alternativas para as suas vidas, este movimento desponta apenas na década de 1980. A sua emergência é o resultado de vários fatores, entre os quais se contam o ano internacional da pessoa com deficiência (1981), as medidas propostas no Programa Mundial para as Pessoas com Deficiência aprovado pela Assembleia Geral das nações Unidas em 1982 (Resolução 37/52, de 3 de dezembro de 1982) e, acima de tudo, o contacto estabelecido entre ativistas pelos direitos das pessoas com deficiência americanos e europeus, de países como a Alemanha, o Reino Unido e a Suécia. O primeiro congresso internacional de Vida independente na Europa, realizado em Munique em 1982, constituiu, precisamente, uma importante plataforma de contacto entre ativistas pela Vida Independente desses dois continentes (Evans, 2003). Em resultado dessa iniciativa, foi criado o primeiro centro de Vida Independente no Reino Unido, o Hampshire Centre for Independent Living, em 1984 e, foi dado início ao primeiro projeto piloto de Vida Independente na Suécia (Estocolmo) em 1987.

Esse movimento, em conjugação com o modelo social da deficiência, tem, ao longo das últimas quase cinco décadas, reconfigurado as políticas sociais na área da deficiência em diferentes países do mundo ocidental. Nesse movimento conjugam-se, sem contradição, alguns dos valores que estruturam o invidualismo moderno e as concepções liberais de autonomia e da responsabilidade individual. O presente artigo, tendo por base uma revisão da literatura internacional e uma análise crítica das políticas na área da deficiência desenvolvidas em Portugal no que concerne à Vida Independente, objetiva, assim, fazer uma arqueologia desse movimento, de forma a situarmos a reivindicação por uma Vida Independente nas agendas do presente das organizações e do movimento de pessoas com deficiência e de forma a refletirmos sobre a forma como a Vida Independente para pessoas com deficiência integra e articula alguns dos valores e concepções dominantes nas sociedades capitalistas ocidentais.

\section{Vida Independente: mobilização e política}

A reivindicação por uma Vida Independente está intimamente ligada ao desenvolvimento e à afirmação do Movimento de Pessoas com Deficiência em países como os Estados Unidos da América (EUA) e o Reino Unido. No caso dos EUA, a demanda pela Vida Independente tem estado na vanguarda das reivindicações do Movimento de Pessoas com Deficiência, desde o final dos anos 1960 (Djong 1979). O seu surgimento deve-se à afirmação da ideia de que as pessoas com deficiência são impedidas de participar na vida da sua comunidade devido a barreiras existentes à sua participação no ambiente físico e social que as rodeia, sendo precisamente uma dessas barreiras o não acesso a serviços de apoio adequados capazes de promover essa participação (Djong, Batavia e Mcknew, 1992). Até à altura os serviços de apoio disponíveis para pessoas com deficiência baseavam-se quer no modelo médico, de que são exemplo as unidades residenciais para pessoas com deficiência, quer em soluções informais por meio do apoio por parte de familiares. O movimento pela Vida Independente emerge, assim, em 
clara oposição a esses modelos tradicionais de apoio que dominavam as suas vidas e cortavam as suas possibilidades de vida, transformando as suas vidas num peso, inadequadas e/ou socialmente inúteis. Num artigo de 1979, Djong identifica a influência de um conjunto de outros movimentos sociais na emergência e consolidação do movimento pela Vida Independente para Pessoas com Deficiência: o movimento pelos direitos civis, o movimento consumerista, o movimento de autoajuda, o movimento pela desmedicalização e o movimento pela desinstitucionalização. Esses movimentos pela forma como tornaram as pessoas com deficiência conscientes dos seus direitos ou de como esses direitos lhes eram negados, empoderados no seu papel de consumidores na definição e administração de serviços pessoais e desafiadores do domínio de profissionais sobre as suas vidas, opondo-se à medicalização da deficiência para além da estabilização médica das suas condições, ajudaram a estruturar a reivindicação por novos direitos, a afirmar uma nova forma de perspetivar a deficiência e a desenvolver novas políticas sociais. Um exemplo desse movimento são as ações desenvolvidas por Ed Roberts e outros estudantes com deficiência na Universidade da Califórnia - Berkeley, nas décadas de 1960 e 1970. Após enfrentar com sucesso a resistência da universidade à sua admissão e instalação, Ed Roberts abre portas à entrada de outros estudantes com deficiência. Este grupo que, mais tarde veio a apelidar-se de 'Rolling Quads', para além de desenvolver uma análise política da sua situação expressa no próprio nome - 'cadeias rolantes', leva a cabo um conjunto de campanhas pelo direito a alojamento autogerido, acesso à comunidade, rebaixamento de passeios, entre outros, ações que permitirão o estabelecimento do Physically Disabled Students Program, primeiro programa nos EUA de serviços para estudantes com deficiência geridos por eles mesmos, e à criação do já referido primeiro centro de vida independente em Berkeley em 1972 (Barnes e Mercer, 2006: 31).

A afirmação da ideia de que o problema não reside na pessoa com deficiência, mas sim nas barreiras ambientais, central ao movimento de vida independente, implicou também uma alteração de papéis sociais desempenhados por parte das pessoas com deficiência, implicou o abandono do papel de clientes e pacientes e a assunção do papel de consumidores (Djong, 1979). Só esta mudança de papéis sociais permite uma efetiva alteração das relações de poder implícitas ao novo modelo de vida independente, e à afirmação do controlo da pessoa com deficiência sobre a sua vida. Essas mudanças encontram-se plasmadas nos serviços oferecidos pelos diferentes centros de vida independente que emergem nos EUA, ao longo da década de 1970, nomeadamente: advocacia, aconselhamento por pares, autoajuda, controlo enquanto consumidor e remoção de barreiras. Esses serviços enquadram, desta forma, uma nova filosofia de vida e uma visão política da condição das pessoas com deficiência na sociedade. As lutas das pessoas com deficiência por uma vida independente ganham reconhecimento federal em 1978, altura em que é publicada a autorização legal para a implementação de serviços de vida independente (Lei PL95-602). Essa lei que vem emendar a anterior legislação sobre reabilitação, adiciona uma nova secção dedicada aos serviços de vida independente em que, para além de outras questões, cria um programa de vida independente a ser oferecido pelos serviços estatais de reabilitação vocacional, bem como um programa de financiamento para os centros de vida independente, para além de permitir a expansão desse novo paradigma e a difusão à escala nacional do modelo dos centros de vida independente. No final da década de 1990 existiriam nos EUA, de acordo com Charlton (1998: 132), mais de 300 Centros de Vida Independente. Segundo o mesmo autor, esses Centros assumiram, ao longo da década de 1980, uma posição central no movimento pelos direitos das pessoas com deficiência nos EUA ao aglutinarem grande parte dos lideres do movimento, ao fornecerem a filosofia de sua base, mas também pelos recursos financeiros e humanos ali disponíveis (Charlton, 1998). Os anos 1990 foram, no entanto, fatais para os Centros de Vida Independente, como também revela Charlton, uma vez que a sua radicalidade, a sua visão estratégica da mudança social a operar se perdeu totalmente, reféns do medo de perder as suas fontes de financiamento (Charlton, 1998: 122). 
O movimento de vida independente na Europa, herdeiro do movimento desenvolvido nos EUA, inicia-se na Inglaterra, ainda durante a década de 1970. Conforme referem Barnes and Mercer (2010), aqui, contrariamente ao movimento encetado nos EUA que se centrou na afirmação do papel das pessoas com deficiência enquanto consumidoras, o Movimento de Pessoas com Deficiência concentrou a sua luta no controlo dos serviços e no controlo das pessoas com deficiência sobre as suas próprias vidas e os serviços que lhes são disponibilizados. Assim, a partir do início da década de 1970, surgem vários grupos organizados de pessoas com deficiência em busca de soluções alternativas de vida na comunidade. Esse movimento deu origem a vários projetos e serviços isolados de autoajuda, de informação e aconselhamento, mas também de assistência pessoal, tendo sempre por base o controlo dos serviços por parte das pessoas com deficiência, culminando na criação dos primeiros centros de vida independente, integrada e inclusiva, conforme as diferentes soluções locais (Barnes e Mercer, 2006). Entre os diferentes projetos, conta-se a criação em 1972 do Grove Road Integrated Housing Scheme (Sutton-in-Ashfield - Derbyshire). Esta iniciativa, resultante de uma longa negociação com serviços e instituições locais, permitiu a instalação num pequeno bloco de apartamentos, de pessoas com deficiência e de famílias de pessoas sem deficiência que, numa lógica de interajuda, disponibilizaram-se a prestar o apoio necessário às pessoas com deficiência (cf. Barnes e Mercer, 2006). Com este mesmo espírito é criada em 1974 a Spinal Injuries Association ${ }^{3}$ (SIA). Essa associação de pessoas com lesão medular oferecia um conjunto amplo de serviços de suporte, atualmente associados à vida independente, nomeadamente: serviços de informação, de aconselhamento, de encaminhamento, e de bem-estar, tendo criado também um serviço de assistência pessoal e de formação de assistentes pessoais (cf. Barnes e Mercer, 2006). Um outro exemplo deste movimento pelo controlo dos serviços por parte do utilizador é o caso do 'Project 81: Consumer Directed Housing and Care' (Barnes e Mercer, 2006). Esse projeto, criado em 1979, em Hampshire, e que acabou por dar origem em 1984 ao, já referido, primeiro Centro de Vida Independente, permitiu, em articulação com o governo local, criar um esquema de pagamentos indiretos para custear o serviço de assistência pessoal a pessoas com deficiência da região (Barnes e Mercer, 2006).

Nos primeiros anos o financiamento desses serviços de assistência pessoal, criados em diferentes partes do país, foi possível por meio de uma complementaridade de financiamentos provenientes dos diferentes governos locais e do governo central, por meio do recurso ao chamado 'Subsídio para cuidado doméstico'4. A partir de meados da década de 1980, a situação começa a mudar com a introdução de medidas restritivas no sistema de segurança social por parte do governo conservador da altura, que levam ao desaparecimento de alguns apoios e à redução de e/ou redefinição dos critérios de acesso e das formas de cálculo de outros (Pearson, 2012). Uma das vítimas dessa alteração política foi precisamente o 'Subsídio para cuidado doméstico', eliminado em 1986. O forte movimento de contestação por parte das pessoas com deficiência que se lhe seguiu, leva o overno inglês a criar o 'Fundo para a Vida Independente $\mathrm{e}^{5}$. Essa medida política, introduzida em 1988, não obstante os problemas de desenho que a afastavam dos princípios da vida independente tal como vinham sendo definidos pelos organismos e grupos de pessoas com deficiência, veio a revelar-se de grande sucesso ao tornar claro os benefícios da criação de um esquema de assistência pessoal para pessoas com deficiência (Pearson, 2012). Não obstante se tratar de uma medida temporalmente limitada (inicialmente prevista para um período de 5 anos) e gerida por uma entidade privada criada para o efeito, o seu êxito derivou precisamente da possibilidade de escolha e controlo das pessoas com deficiência sobre as suas próprias vidas, que por meio de pagamentos diretos viram materializada a possibilidade de contratação de assistentes pessoais e de uma vida na comunidade, como clara alternativa à vida em unidades residenciais. Em 1992, altura em que terminava o tempo de vida desta medida tal como havia sido pensada, ela é revista e estendida temporalmente.

3 Associação de Lesionados na Coluna Vertebral

4 'Domestic Care Allowance' no original.

5 'Independent Living Fund' no original. 
A partir do final dos anos 1990, as políticas de deficiência na Inglaterra sofreram, no entanto, uma viragem cujo impacto não deixou de se fazer sentir ao nível da vida independente, assim foram feitas várias tentativas para fechar o Fundo para a Vida Independente, alegando que, desde o levantamento do impedimento da realização de pagamentos diretos por parte dos governos locais em 1996, e a introdução dos 'orçamentos individuais' ${ }^{3}$ e dos pagamentos diretos ${ }^{7}$, não fazia sentido uma duplicação de financiamentos. A vitória da coligação entre conservadores e liberais democratas em 2010, veio afirmar este propósito, impedindo o acesso de novos/as utilizadores/as ao programa a partir do final de 2010, decretando o encerramento total da medida em 2015 (Roulstone e Prideaux, 2012; Department for Communities and Local Government, 2016) e transferindo todos/as os/as utilizadores para a responsabilidade dos governos locais. A oposição dos/as utilizadores/as e do movimento de pessoas com deficiência, bem como das ações e decisões judiciais interpostas face a esta intenção, não impediram, no entanto, o encerramento desta medida de política em junho de 2015, conseguiram, todavia, o compromisso do governo central no financiamento das autoridades locais para suporte dos/as utilizadores/as do antigo Fundo para a Vida Independente até 2019-2020 (Jarrett, 2018). O encerramento do Fundo para a Vida Independente e a transferência de responsabilidades para os governos locais, colocou, assim, mais uma vez, as pessoas com deficiência numa situação de grande vulnerabilidade face a possíveis cortes. Como foi largamente difundido essa transferência para os governos locais não foi limitada na sua utilização aos beneficiários/ as da antiga medida ou a esse propósito o que gerou cortes no apoio prestado nalgumas partes do país, criando disparidades entre diferentes regiões e comprometendo seriamente o futuro da vida independente, a que correspondeu uma desvalorização do papel dos existentes Centros de Vida Independente/ Integrada ou Inclusiva face à competição no acesso aos contratos de financiamento junto dos governos locais que levou, mesmo, ao declínio do número destes centros (Oliver e Barnes, 2012). O país pioneiro na implementação da Vida Independente para Pessoas com Deficiência a nível europeu encontra-se, atualmente, numa situação de extrema fragilidade e incerteza quanto ao futuro na efetivação deste direito consagrado na Convenção dos Direitos das Pessoas com Deficiência.

Nos restantes países europeus o movimento pela vida independente tem sido bastante desigual, com diferentes ritmos e pautado por avanços e recuos, com países como a Suécia a liderarem esse movimento e com os países da europa central, com uma forte tradição institucionalista, e os países do sul da Europa, com uma forte tradição familista, na cauda desse movimento. ${ }^{8}$ Esta inconstância é ela mesma um resultado da volubilidade e da fraqueza das orientações políticas por parte das instituições europeias. Como veremos, não obstante as orientações no sentido da vida na comunidade e de forma independente para pessoas com deficiência remontarem pelo menos a 1988, quando do lançamento do $2^{\circ}$ Programa de Ação para a Deficiência, por parte da então Comunidade Econômica Europeia, vulgarmente apelidado de Programa HELIOS (1988-1991) (Council Decision 88/231/EED of 18 April 1988) mas com a denominação 'Handicapped People in the European Community Living Independently in an Open Society' ${ }^{9}$, continuamos ainda hoje a assistir à sua afirmação enquanto princípio mas não enquanto obrigação para os diferentes países europeus, como é visível na orientação da utilização dos fundos estruturais e de investimento europeus no sentido da desinstitucionalização e da promoção da vida na comunidade.

6 'Individual budgets' no original.

7 Comunity Care Act (1996).

8 Para uma análise aprofundada da situação dos diferentes países europeus, consultar: https://www.disability-europe. net/theme/independent-living?

9 "Pessoas com incapacidade na Comunidade Europeia vivendo de forma independente numa sociedade aberta", tradução livre dos autores. 


\section{0 contexto português}

Em Portugal, não obstante esta reivindicação datar da segunda metade da década de 1990 (Associação, 1996: 4), só ganhou folgo no Movimento de Pessoas com Deficiência no início da década de 2010, maioritariamente por meio do coletivo '(D)eficientes Indignados' que desenvolveu um conjunto diversificado de ações políticas de reivindicação pelo direito à Vida Independente, em que se incluem marchas, manifestações, debates, mobilização por meio das redes sociais e acampamentos frente à Assembleia da República. Essa mobilização e pressão política dará origem ao primeiro Centro de Vida Independente, criado em Lisboa no final de 2015, e ao primeiro projeto-piloto de Vida Independente, criado e financiado pela Câmara Municipal de Lisboa e iniciado em dezembro de 2015. Em 2017 o Governo Português aprovou o programa "Modelo de Apoio à Vida Independente" (MAVI) por meio do qual pretendeu efetivar o direito das pessoas com deficiência à Vida independente (Decreto-Lei no 129/2017, de 9 de outubro). Esta medida de política permitiu a criação de "Centros de Apoio à Vida Independente" (CAVIs) em diferentes partes do país e o arranque de projetos-piloto de Vida Independente, ao longo do primeiro trimestre de 2019. Tal como definido, estes projetos-piloto com uma duração esperada de 3 anos serão alvo de um processo de avaliação conducente à preparação e aprovação de uma lei de vida independente para pessoas com deficiência em Portugal. O Governo Português foi, no entanto, muito contido na medida aprovada, limitando-a uma iniciativa legislativa e não de um direito conferido às pessoas com deficiência em Portugal, demasiado normativo no desenho da medida, impondo o modelo a implementar em vez de permitir uma maior autonomia na estruturação do serviço capaz de testar diferentes soluções, e pouco generoso na alocação de meios, limitando o alcance e impacto dos projetos-piloto na vida das pessoas com deficiência por maio da alocação de recursos financeiros insuficientes para fazer face às necessidades reais das pessoas com deficiência e à efetivação do estipulado no articulado legal. Exemplo deste último facto é, por exemplo, a possibilidade de um máximo de 30\% dos/as utilizadores/as por CAVI poderem ter até 24 horas de assistência pessoal diárias, quando o orçamento disponibilizado inviabiliza totalmente essa hipótese. Estamos, assim, face a uma medida de política de curto alcance e de impacto limitado.

Em Portugal, como noutros países europeus, a afirmação do direito à Vida Independente resulta, maioritariamente, da aprovação da Convenção sobre os Direitos das Pessoas com Deficiência (CDPD) em 2006. A CDPD ao consagrar no seu artigo $19^{\circ}$ o direito das pessoas com deficiência a uma vida independente e a viverem na comunidade, criou, um imperativo legal aos Estados signatários para efetivarem esse direito. Esse imperativo foi reforçado em 2017 pelo Comité sobre os Direitos das Pessoas com Deficiência, responsável pela monitorização da implementação da CDPD por parte dos Estados signatários, com a publicação do Comentário Geral no 5 . Este documento, para além de definir o que significa a Vida Independente, de clarificar os princípios e ideias que estão na sua base e que devem nortear a sua implementação, de esboçar o caminho a seguir pelos Estados, define também a obrigação dos Estados signatários de garantirem o não investimento público e/ou privado na renovação, construção ou criação de quaisquer instituições para pessoas com deficiência ou de soluções de vida ou serviços baseados na sua institucionalização, investimento esse que deverá ser canalizado para serviços que consubstanciem o direito à Vida Independente e na comunidade (CRPD, 2017). Neste mesmo sentido aponta a Estratégia Europeia para os Direitos das Pessoas com Deficiência (2021-2030 ${ }^{10}$. Essa estratégia, embora recorrendo a soft law, define o acesso a uma vida decente e à vida independente com uma das oito áreas prioritárias, emitido indicações claras no sentido da desinstitucionalização das pessoas com deficiência e à criação de serviços e oportunidades de vida na comunidade e habitação acessível. As diferentes iniciativas europeias ao nível da deficiência, incluindo a estratégia

10 Disponível em: file://C:/Users/fernando/Downloads/KE0221257ENN_002\%20proof\%202\%20(1).pdf 
2021-2030, pecam, no entanto, pelo seu caracter não impositivo, o que continua a comprometer a concretização plena dos objetivos definidos, a implementação da CDPD e a maximização da aplicação dos fundos europeus estruturais e de investimento para esses fins. Assim, não obstante a pressão por parte da Rede Europeia de Vida Independente (ENIL) no sentido da utilização destes fundos para a desinstitucionalização e desenvolvimento de soluções de vida na comunidade para pessoas com deficiência, a ausência de um compromisso e de diretivas europeias claras continua a alimentar soluções de vida para as pessoas com deficiência que violam os princípios da autonomia, do controlo e da autodeterminação.

O movimento pela vida independente para pessoas com deficiência a nível europeu tem sido liderado pela 'Rede Europeia de Vida Independente' (ENIL). Esta organização europeia que agrega organizações de pessoas com deficiência e ativistas pelo direito à vida independente de diferentes países europeus, tem desenvolvido um importante trabalho de disseminação da vida independente e dos seus princípios junto das instâncias europeias, mas também de orientação das organizações e movimentos de pessoas com deficiência nos diferentes países. Como o caso português revela, estas organizações e movimentos enfrentam, no entanto, crescentes resistências e dificuldades na implementação da filosofia e princípios de Vida Independente. Identificamos três principais níveis de resistências e dificuldades por parte do movimento e organizações de pessoas com deficiência em Portugal: um primeiro nível de resistência de cariz governativo, um segundo nível de cariz associativo e um terceiro nível relacionado com a mobilização e apoio das bases, i.e. das pessoas com deficiência.

A nível governativo assistimos a uma crescente valorização das questões relacionadas com a deficiência e a uma maior presença da deficiência nos discursos e políticas. Esta crescente presença, cuja face mais visível é a ascensão de pessoas com deficiência a lugares governamentais de decisão, resulta da aprovação de documentos estratégicos internacionais, como a CDPD, e da consequente afirmação da linguagem dos direitos humanos. A novidade destas agendas, a sua contradição com a organização institucional estabelecida e legitimada ao longo de décadas por parte de um Estado Social fraco e dependente do terceiro sector para prestação de serviços à população, a ausência de diretivas europeias claras relativamente ao sentido das mudanças a operar na área da deficiência, e o desconhecimento generalizado da população portuguesa relativamente à Vida Independente para pessoas com deficiência, impede a implementação de mudanças significativas nas políticas de deficiência em Portugal, compromete a implementação dos princípios da Vida Independente bem como a utilização dos fundos estruturais e de investimento para promover a desinstitucionalização e a vida na comunidade e torna as agendas políticas permeáveis a influências estabelecidas e a ideologias individuais dos membros do governo.

A nível associativo assistimos a uma apropriação dos conceitos chave e propostas políticas desenvolvidas pelo movimento de pessoas com deficiência por parte do sector organizativo tradicional na área da deficiência, composto por organizações para pessoas com deficiência. Esta apropriação, resultante da legitimação política destas propostas em documentos estratégicos internacionais como a CDPD, apresenta-se problemática pelo desvirtuamento das ideias originais que ocorre neste processo de apropriação e adequação aos interesses deste setor tradicional e pela aparente indissociação de ideias entre os diferentes sectores organizativos na área da deficiência e a tendencial sobrevalorização das vozes do sector tradicional, melhor organizado, melhor implantado no território nacional, com maior massa crítica profissionalizada e credor da delegação estatal de responsabilidades. Tal como assinalado anteriormente, a ausência de diretivas claras sobre a forma como interpretar e implementar estas novas ideias e soluções políticas torna-as permeáveis a reinterpretações por parte dos diferentes sectores. Acresce que, em países como Portugal, onde historicamente o Estado é altamente devedor das iniciativas e serviços prestados pelo sector tradicional da deficiência, existe uma maior apetência para legitimação política das suas ideias e propostas e salvaguarda dos seus interesses. Tomando como exemplo a implementação da recente medida de política social 'Movimento de Apoio à Vida Independente' (MAVI), não são despiciendas as exigências organizativas impostas à criação dos Centros de 
Apoio à Vida Independente (CAVIs), atualmente em curso enquanto projetos-piloto, nomeadamente a exigência de constituição enquanto IPSS (Instituição Particular de Solidariedade Social) e detenção do estatuto de ONGPD (Organização Não Governamental de Pessoas com Deficiência), que impediram a emergência de iniciativas por parte de coletivos de pessoas com deficiência e fomentou a emergência de iniciativas por parte de organizações tradicionais para pessoas com deficiência. Do total de 35 CAVIs criados em Portugal no âmbito do Movimento de Apoio à Vida Independente (MAVI) apenas 4 são desenvolvidos pelo coletivo de pessoas com deficiência - Centro de Vida Independente (CVI) - desenvolvido inicialmente como organização local para implementar o projeto-piloto de vida independente de Lisboa encetado em 2015 e que posteriormente se transformou em organização de âmbito nacional para possibilitar o seu acesso à criação de CAVIs em diferentes partes do país, as restantes iniciativas são desenvolvidas por organizações tradicionais para pessoas com deficiência.

Ao nível da mobilização e apoio das bases, assistimos a uma alienação individual por parte das pessoas com deficiência face às causas coletivas que mobilizam o movimento e as organizações de pessoas com deficiência em Portugal o que compromete o poder reivindicativo do movimento, mas também a própria renovação dos quadros do movimento associativo. Tal situação é o resultado de uma confluência de diferentes fatores. Em primeiro lugar, uma dificuldade de coletivização dos problemas individuais resultante de uma falta de politização e da não garantia de condições mínimas de igualdade de vida por parte do Estado. Em segundo lugar, um deslumbramento face às novas medidas de política, nomeadamente a possibilidade do serviço de assistência pessoal, após várias décadas de alienação política e social face aos problemas das pessoas com deficiência em Portugal. Em terceiro lugar, um desconhecimento quase generalizado da filosofia, dos princípios orientadores e da luta que está na base da Vida Independente, gerador de uma maior aceitação e de ausência de reflexão crítica face à estratégia e propostas do governo para implementar a vida independente em Portugal.

É, assim, neste contexto que o movimento de pessoas com deficiência e o movimento pela vida independente atualmente se movem, com as dificuldades daí resultantes, cujas marcas são visíveis no impasse na efetivação dos direitos consagrados pela Convenção dos Direitos das Pessoas com Deficiência. $\mathrm{Na}$ análise deste impasse importa refletir de uma forma mais ampla sobre os valores e os princípios que estruturam uma Vida Independente e sobre a forma como nesta filosofia de vida se articulam alguns dos valores e conceções dominantes nas sociedades capitalistas ocidentais, que, por um lado, facilitam a sua difusão e, por outro, desarmam e esvaziam o movimento que lhe deu origem.

\section{Princípios e filosofia da Vida Independente}

A Vida Independente tem-se sedimentando internacionalmente enquanto a defesa de que as pessoas com deficiência devem ter o controlo sobre todas as decisões que dizem respeito às suas vidas. Trata-se de proclamar o direito a viverem em contextos em que não sejam subjugadas pelas lógicas da dependência do cuidado familiar ou das soluções oferecidas em contextos institucionais que, sem atenderem às suas especificidades, as colocam numa situação de vulnerabilidade, impedindo-as de tomar decisões em relação às suas vidas. Como referem Barnes e Mercer, a Vida Independente significa "todas as pessoas com deficiência terem a mesma escolha, controlo e liberdade como qualquer outro cidadão - em casa, no trabalho e como membros da comunidade. Isto não significa necessariamente que as pessoas com deficiência façam tudo por si próprias, mas significa que qualquer assistência prática requerida tem de estar sob o controlo da pessoa com deficiência” (2006:33). Conforme clarifica Morris (2003) esta definição incorpora três dos principais elementos que devem estruturar a Vida Independente para Pessoas com Deficiência : a ideia de igualdade de direitos entre pessoas com e sem deficiência, expressa na asserção de todas as pessoas com deficiência terem a mesma escolha, controlo e liberdade como qualquer outro cidadão; a ideia de que ser independente não significa fazer tudo por si próprio/a e, a ideia da escolha e controlo sobre tudo aquilo que é prestado. Auto-determinação, igualdade, escolha e controlo são, assim, 
quatro dos princípios basilares da filosofia de vida independente para pessoas com deficiência, que se baseia numa mudança paradigmática expressa numa ênfase nos direitos em detrimento da caridade, na inclusão em detrimento da exclusão e da segregação e na afirmação de uma cultura de aceitação das pessoas com deficiência como cidadãs e cidadãos com igualdade de direitos em detrimento de uma cultura de dependência e de pena (cf. Barnes e Mercer, 2006).

Tal como clarifica Morris (2003: 5), a igualdade de direitos pressuposta no modelo de vida independente não significa, no entanto, que as pessoas com deficiência sejam iguais às pessoas sem deficiência, significa apenas que têm os mesmos direitos e que devem ser criadas condições para a sua efetivação e gozo por parte de todas e de todos que tenham em conta as suas necessidades. As pessoas com deficiência têm necessidades adicionais face às pessoas sem deficiência, resultantes da sua condição individual e das barreiras sociais que lhes são impostas, que é necessário garantir para efetivar esta igualdade de direitos. O coletivo de pessoas com deficiência tem procurado ao longo dos tempos sistematizar essas necessidades. Em 1986 a Derbyshire Coalition of Disabled People identifica sete necessidades das pessoas com deficiência a que é necessário responder de forma a aperfeiçoar os serviços da comunidade e a promover a independência das pessoas com deficiência, em que se incluem necessidades de: informação, apoio por pares, habitação, ajudas e equipamento técnico, assistência pessoal, transporte e acessibilidade (DCODP, 1986; Davis and Mullender, 1993). Esta lista foi sendo atualizada ao longo dos tempos por outros coletivos de forma a responder às necessidades emergentes das pessoas com deficiência, mas revela sobretudo que negar a satisfação dessas necessidades significa negar às pessoas com deficiência o exercício de direitos políticos, civis, sociais e, como estabelece a CDPD, os seus direitos humanos.

Como é possível verificar nesta lista e nas atualizações que lhe sucederam, a escolha e controlo essenciais à filosofia de Vida Independente aplicam-se, não só ao ambiente em que a pessoa vive, mas também à assistência ou ao apoio de que a pessoa necessite para exercitar os seus direitos. Os princípios da escolha e do controlo que presidem à filosofia de vida independente apresentam uma relação simbiótica com dois outros fatores essenciais ao exercício dos primeiros: a eliminação de barreiras existentes na sociedade e a disponibilização de assistência pessoal. Na esteira do modelo social da deficiência, que concebe a deficiência como um fenômeno socialmente produzido de exclusão e opressão de pessoas com deficiência por parte da sociedade em geral por meio da criação de barreiras sociais, económicas, psicológicas e físicas, a filosofia de Vida Independente vem afirmar a eliminação destas mesmas barreiras identificadas pelo modelo social como crucial à sua efetivação. Tal a filosofia de vida independente pressupõe não é suficiente a existência de uma igualdade formal tal como tem sido realidade na grande maioria dos países, uma vez que estas barreiras incapacitam e impedem as pessoas com deficiência de exercitar os seus direitos e de participar na vida da comunidade, fazendo na prática com que a maioria das pessoas com deficiência veja os seus direitos de cidadania. É, assim, necessária uma igualdade substantiva que se baseie na eliminação das diferentes barreiras incapacitantes existentes na sociedade, no reconhecimento da igual dignidade e dos direitos humanos das pessoas com deficiência, na eliminação dos fenômenos de exclusão, opressão e de assimetria de poder vivenciados pelas pessoas com deficiência. Essas mudanças terão de ser necessariamente transversais aos diferentes ambientes sociais e institucionais, implicando a remoção de barreiras físicas, mas também de barreiras culturais e de assimetrias de poder que colocam as pessoas com deficiência, na grande maioria dos casos, em posições subalternas e de grande fragilidade, em casa, na escola, no trabalho, na relação e participação na comunidade e nas instituições.

Urge, desta forma, afirmar a primazia da autonomia e liberdade de ação individual, perigosamente próxima dos princípios de um modelo liberal de cidadania (Held, 2006), mas afastando-se deste ao afirmar a primazia do Estado enquanto principal motor desta transformação. Como reflete Jenny Morris a "Incapacidade e as barreiras deficientizadoras impõem limites na liberdade de ação, sendo assim necessária uma ação positiva [por parte do Estado] para promover oportunidades de auto-de- 
terminação."11 (2005: 26). Efetivamente, o papel do Estado é essencial, na eliminação destas barreiras por meio da emanação de princípio legais que confirmem e legitimem os direitos das pessoas com deficiência e zelem pelo seu exercício e respeito, bem como no desenvolvimento de políticas sociais consentâneas com os princípios de vida independente e que consubstanciem uma igualdade substantiva por meio do desenvolvimento de iniciativas promotoras de oportunidades de auto-determinação. A vida independente enquanto medida de política, ao se basear nos princípios da escolha e controlo, constitui um importante exemplo de potenciais ações positivas por parte dos Estados. Importa, no entanto, que estas medidas de política se mantenham fiéis à filosofia original emanada do movimento no seu desenho e implementação, uma vez que o seu desvirtuamento poderá levar ao comprometimento do seu potencial positivo, como acontece no caso português. Em Portugal o desenho e implementação do Modelo de Apoio à Vida Independente (MAVI) que enquadra a criação dos Centros de Apoio à Vida Independente (CAVIs), pela ausência de pagamentos diretos às pessoas com deficiência, pela limitação do número de horas de assistência pessoal, pela necessidade de partilha de assistentes pessoais, pelos requisitos legais à constituição dos CAVIs que mantiveram o seu controlo e gestão maioritariamente na mão de profissionais, negou os princípios da escolha e controlo, comprometeu o potencial transformador da medida, e, de forma mais gravosa, empenhou o potencial de auto-determinação destes projetos na vida das pessoas com deficiência.

O exercício da escolha e controlo ao nível da assistência e do apoio requerido pelas pessoas com deficiência no exercício dos seus direitos e do seu dia a dia , como qualquer outra pessoa, só é possível, em alguns casos, por meio da disponibilização de assistência pessoal. A assistência pessoal consubstancia-se na contratação de uma pessoa para apoiar a pessoa com deficiência nas tarefas e responsabilidades do seu dia a dia, resultantes quer do nível e tipo de incapacidade, quer das barreiras deficientizadoras do meio. Ou a assistente pessoal constitui, assim, uma extensão da pessoa com deficiência no exercício das tarefas e das atividades do dia a dia que a pessoa com deficiência não consegue fazer. A definição do seu âmbito e do tempo necessário ao seu desenvolvimento depende, assim, das necessidades individuais de cada pessoa. Isto significa que, de forma a permitir o acesso a uma vida independente, o número de horas diárias de assistência pessoal e o tipo de tarefas a desenvolver deve ser definido de forma individual e respeitando as necessidades individuais. Acresce que a pessoa com deficiência deve ter o controlo sobre todo o processo desde a definição do apoio a ser prestado, passando pela seleção, contratação e formação do ou da assistente pessoal, até à gestão da assistência pessoal. A escolha e controlo neste processo só é possível por rmeio da facilitação de pagamentos diretos às pessoas com deficiência. A transferência financeira direta do Estado para essas pessoas permite-lhes exercitar os seus direitos sem interferência ou imposição de terceiras entidades, cabendo aqui aos centros de vida independente, ou 'de apoio à vida independente' como se optou em Portugal, um papel de apoio de retaguarda, oferecendo às pessoas com deficiência serviços de educação e aconselhamento sobre contratação, apoio e aconselhamento por pares e aconselhamento e apoio na gestão da assistência pessoal. A efetivação da vida independente deve ser, assim, o foco desta medida de política e não os centros de 'apoio' à vida independente, uma vez que estes são instrumentos de retaguarda e a sua constituição deve ser deixada à iniciativa das pessoas com deficiência. Só desta forma será possível garantir a criação de um serviço potenciador da auto-determinação das pessoas com deficiência e não fomentador na manutenção de iniciativas geridas por entidades terceiras não controladas pelas pessoas com deficiência.

O caracter imperativo desta mudança paradigmática nas políticas sociais na área da deficiência tem sido publicamente reconhecido por documentos estratégicos internacionais, como a já referida Convenção sobre os direitos das Pessoas com Deficiência adotada na Assembleia Geral das Nações Unidas em dezembro de 2006 e a recentemente apresentada Estratégia Europeia para os Direitos das Pessoas

11 No original: "Impairment and disabling barriers impose limits on freedom of action and positive action is therefore required to deliver opportunities for self-determination". 
com Deficiência 2021-2030, importa, pois, efetivar esta mudança pelo seu potencial de transformação positiva nas vidas das pessoas com deficiência. Não obstante as dificuldades anteriormente identificadas, a sua eficácia na emancipação dessas pessoas tem sido aferida em vários países onde esta medida de política tem vindo a ser implementada (Hutchison et al. 2000; Townsley, 2010; White et al. 2010).

\section{Autodeterminaç̃ão em tempos de capitalismo neoliberal}

Como referimos anteriormente, os princípios de escolha e controlo pressupostos pela filosofia de vida independente que procura efetivar a autodeterminação e autonomia das pessoas com deficiência, têm sido, muitas vezes, associados às políticas consumistas e a modelos de democracia liberal (Morris, 2005; Barnes e Mercer, 2006). A importância de a vida independente confrontar as lógicas instauradas pelo capitalismo e pelo neoliberalismo é tão mais crucial se tivermos em conta como este sistema económico e social é estruturante quer da invenção moderna da deficiência, quer das relações de opressão que concorrem para a exclusão social das pessoas com deficiência.

As teias de sentido por via das quais a deficiência veio a ser definida na modernidade consagram como central uma a objectificação medicalizada de determinados corpos e formas de habitar o mundo. No entanto, dificilmente poderemos aceder às implicações dessa narrativa histórica, a menos que contemplemos a intervenção de outras transformações que vieram habitar a casa da modernidade. Destacamos dois elementos que foram parte dessa metamorfose cultural: o capitalismo industrial, uma transformação radical nos modos de produção dominantes, e o individualismo, uma alteração não menos radical nas formas de apreensão e valorização dos sujeitos.

As transformações ocorridas na economia produtiva surgem como um elemento absolutamente fulcral na marginalização social das pessoas que viriam estar reunidas sob o conceito de deficiência. Como já analisamos, é bem verdade que o período pré-industrial está longe de nos oferecer um retrato idílico no que concerne integração social das pessoas cegas, isto, muito por culpa da miríade de associações e crenças reinantes. Não obstante, permanece enquanto válida a persuasão de que na pré-modernidade as "pessoas com deficiência" contribuíam para as atividades produtivas, realizadas em contextos familiares, na agricultura e nas pequenas manufaturas. Esses contextos que permitiam que todos dessem o seu contributo consoante as suas características específicas e os seus ritmos particulares.

A revolução industrial e o subsequente desenvolvimento dos processos industriais trouxe uma abrupta transformação daquelas que eram as condições de produção vigentes até o século XVIII. A partir dessa altura surgiram contextos profundamente estandardizados e inflexíveis às diferenças individuais. Emergiu um sistema de produção cujos padrões se inconciliam com a participação das pessoas com deficiência, legando-as à completa exclusão da economia produtiva ou, na melhor das hipóteses, a uma residual contribuição no seio das muitas "instituições totais" que se criaram a partir do século XVIII para albergar as diversas deficiências. De facto, o advento da industrialização vem tornar o corpo da pessoa deficiente demasiado "presente", excessivo nos seus défices, na sua disparidade para com a norma corporal, incapaz de se adequar aos novos imperativos laborais:

A velocidade do trabalho fabril, a disciplina imposta, as normas de produção e de poupança de tempo - todas estas foram transformações altamente desfavoráveis em relação aos métodos de trabalho mais lentos, mais autodeterminados e flexíveis, em que as pessoas com handicaps tinham estado integradas. (Oliver, 1990: 27). O surgimento de uma rigorosa disciplina na atividade fabril e a imposição de uma lógica de maximização do rendimento, implicou que o corpo humano se constituísse largamente como uma extensão da maquinaria industrial na realização de práticas estandardizadas. Daqui emerge uma visão mecanicista e funcional do corpo, que é feito parte de um dispositivo complexo, repetitivo e que se estabelece por referência central a uma optimização da rentabilidade na produção.

O que se torna crucial para este âmbito é o facto de o processo industrial ter estado ligado a uma nascente definição do corpo em termos de capacidade produtiva e a uma emergente concepção acerca 
de uma perfeição mecânica do corpo humano (Davis, 1995: 87). Numa primeira instância, este fenômeno conduziu a uma efectiva exclusão das pessoas incapazes de se adaptarem às condições de produção estabelecidas ou que estivessem abaixo de um determinado padrão de produtividade. No entanto, a emergência de uma concepção mecanicista do corpo acarretaria também implicações decisivas ao nível das representações culturais. Delas destacamos o modo como esta concepção viria a infundir as noções de normalidade promovidas no âmbito da ciência médica. Claudine Herzlich (1991: 206) aponta exatamente para esta questão quando sublinha a influência constituída pelo regime de trabalho que acompanhou o desenvolvimento industrial, no surgimento de uma associação entre saúde e capacidade de trabalho e, por oposição, entre doença e inaptidão laboral. Despertamos assim para o facto de que o modelo biomédico do corpo, a estabelecida norma na regulação dos discursos e práticas da Medicina, encontra-se ancorado, desde a sua origem, pelas concepções mecanicistas do corpo geradas a partir da revolução industrial. No entanto, um aspeto que devemos ter em conta para além de uma leitura eurocêntrica sobre a modernidade, é o modo como a capacidade de trabalho e a aptidão física se encontram fortemente intricados na economia produtiva associada ao tráfico transatlântico de pessoas escravizadas. Os corpos negros minuciosamente escrutinados em leilões de escravizados substanciam uma importante genealogia moderna entre, por um lado, escravidão e capitalismo industrial ${ }^{12}$ e, por outro, o corpo escravizado apto para o trabalho da plantação ou da mineração e o corpo normal que integrou a economia política do capitalismo industrial (Hunt Kenedy, 2020)

Um outro elemento que se torna incontornável para a nossa análise reside na assunção do individualismo enquanto um valor que veio a permear decisivamente o "sentido do ser" no Ocidente. Na verdade, a emergência do individualismo encontraria um estreito parentesco com a emergência do capitalismo industrial. Basta atentar para o facto de que ambos se consagraram a par com as visões liberais promovidas com a ascensão do poder da burguesia. No entanto, se por um lado é saliente a importância que as concepções individualistas detêm nas possibilidades de articulação das garantias políticas e sociais dos sujeitos, por outro elas são nutridas e tomam parte de uma lógica que permeia o tecido social engendrando outro tipo de constrangimentos. Concretamente, ao trazer aqui a questão do individualismo moderno procuramos relacionar essa construção com a deficiência e a vida independente a partir de duas linhas de análise distintas. A primeira liga-se à identificação do individualismo como uma elaboração cultural que desempenhou um papel central para que as implicações e respostas pensáveis à deficiência se confinassem a um olhar centrado no indivíduo: a pessoa com deficiência. Este enfoque opõe-se a problematização das estruturas sociais opressoras em que a deficiência ganha significado e em que se mapeiam as vivências das pessoas com deficiência. A segunda linha de análise envia-nos para a relação entre os valores promovidos pelo individualismo e as emergentes formas de valorização social das pessoas.

Partindo da primeira abordagem referida, acima de tudo importa perceber como a afirmação do "paradigma das limitações funcionais" na apreensão cultural das pessoas deficientes é permeada e reforçada pelos valores do individualismo moderno. Em causa está uma ênfase nas condições e capacidades do indivíduo que tende a subvalorizar a relação entre as possibilidades individuais e os contextos que as estruturam. Emerge assim uma asserção profundamente paradoxal. Por um lado, é central contemplar o lugar ocupado pela reivindicação dos direitos individuais das pessoas cegas, mormente o direito ao emprego, à educação e à segurança econômica. Neste caso os valores individualistas mostram ser uma plataforma de sentido para que as pessoas cegas possam confrontar as formas de opressão e discriminação a que estão sujeitas. Por outro lado, os processos que reduziram as implicações da deficiência a uma narrativa de limitações individuais terão que ser entendidos, não como um assalto à individualidade humana, mas ao próprio itinerário de sentido por meio do qual a individualidade ganha uma fundação.

12 Bastará lembrar o célebre trabalho de Eric Williams, Capitalism é Slavery, em que o autor mostra como o capital cumulado pela exploração escravacrata foi essencial para o financiamento da revolução industrial em Inglaterra e, por consequência, para a implantação do capitalismo industrial que estabeleceu pelo mundo nos últimos séculos. 
No que se refere à relação entre o individualismo e as formas de valorização social prescritas na modernidade ocidental, fica claro que celebração moderna do indivíduo e da sua capacidade de realização se mostram particularmente opressivos para as pessoas com deficiência. A ênfase que os valores do individualismo colocam na capacidade individual de realização marcam, quase inescapavelmente, os investimentos, aspirações, frustrações, preocupações e ansiedades que pontuam as vivências das mulheres e homens modernos. De facto, a desvalorização pessoal e social que resulta da dependência de outrem, mesmo nas mais triviais realizações quotidianas, torna-se amiúde uma questão problemática para as pessoas com deficiência. Isso ocorre, quer porque a realização autônoma de determinadas atividades se torna inviável em face de diferenças funcionais, quer porque a necessidade de apoio em determinadas tarefas expõe muitas vezes a pessoa com deficiência a atitudes paternalistas e menorizadoras. Isto é tão mais relevante num quadro em que respostas sociais dominantes à deficiência instigam os sujeitos a uma heroica superação pessoal, num óbvio menosprezo das transformações passíveis de serem empreendidas no meio cultural, social e físico.

\section{Conclusão: solidariedade e resistência}

Após algumas décadas em que, com o continuado crescimento das despesas sociais, a conciliação entre acumulação e distribuição parecia uma real possibilidade no seio do Estado Social, assistimos ao início da sua crise, nos países da sua criação, a partir dos anos 1970. Trata-se de uma continuada crise que veio a colocar em causa a ideia de que a acumulação infinita se pode concertar com a permanência ou ampliação dos direitos sociais; nesse sentido verifica-se que "o capitalismo avançado que criou o Estado Providência se distancia progressivamente desta sua criação” (Santos, 1990: 205). A retração das políticas sociais aparece-nos assim como um fatalismo da economia capitalista, num processo que, como sabemos, muito tem devido à desregulação levada a cabo sob a égide neoliberal.

Como prova a luta histórica das pessoas com deficiência, concitando uma coletivização das experiências individuais de opressão e expondo a crucial interdependência de que depende a defesa do Estado Social ante a ascensão do neoliberalismo individualista, a afirmação da vida independente é uma forma de resistência às estruturas do capacitismo mas liga-se igualmente à hegemonia valores individualistas e neoliberais. Há, portanto, um caminho de transformação social mais ampla que reclama por uma desestabilização das representações dominantes da deficiência e por uma vitalidade democrática que, longe de qualquer individualismo, funda-se nos valores da solidariedade e na mobiliação coletiva. Só essa vitalidade nascida dos movimentos de pessoas com deficiência poderá colocar a vida independente no coração das lutas contemporâneas por dignidade e direitos humanos, ao mesmo tempo que ilumina o regime de exclusão perpetrado pela articulação histórica entre capacitismo, capitalismo e individualismo neoliberal.

\section{Agradecimentos}

Este artigo resulta do trabalho de investigação desenvolvido no âmbito do projeto DECIDE - Deficiência e autodeterminação: o desafio da Vida Independente em Portugal. Este projecto tem o apoio financeiro da Fundação para a Ciência e Tecnologia (FCT/MEC) através de fundos nacionais e é cofinanciado pelo FEDER através do Programa Operacional Competitividade e Inovação COMPETE 2020. Projeto PTDC/IVC-SOC/6484/2014 - POCI-01-0145-FEDER-016803. Este artigo contou, ainda, com o apoio da Fundação para a Ciência e a Tecnologia, ao abrigo do contrato de trabalho no âmbito da Norma Transitória (DL57/2016/CP1341/CT0007) e do contrato da CEEC Individual com a referência 2020.01127.CEECIND/CP1627/CT0004. 


\section{Referências:}

Barnes, C., Mercer, G. 2006. Independent Futures - Creating user-led disability services in a disabling society. Bristol: The Policy Press.

Charlton, James I. 1998. Nothing about us without us - Disability Oppression and empowerment. London: The University of California Press.

Committee on the Rights of Persons with Disabilities (2017). General comment No. 5 (2017) on living independently and being included in the community. 27 October 2017. Available at: https://www. ohchr.org/en/hrbodies/crpd/pages/gc.aspx

Davis, Lennard (1995), Enforcing Normalcy: Disability, Deafness and the Body. Londres: Verso.

DEJONG, G., BATAVIA, A., \& MCKNEW, L. (1992). The Independent Living Model of Personal Assistance in National Long-Term-Care Policy. Generations: Journal of the American Society on Aging, 16(1), 89-95. Retrieved May 11, 2021, from http://www.jstor.org/stable/44877066

Djong, Gerben 1979. Independent Living: From Social Movement to Analytic Paradigm. Archives of Physical Medicine and Rehabilitation, Oct 1979, 60(10):435-446.

Eric Williams (2014/1944), Capitalism and Slavery, Chapel Hill: University of North Carolina Press.

Evans, John. 2003. “The Independent Living Movement in the UK." Internet publication URL: www. independentliving.org/docs6/evans2003.html.

Herzlich, Claudine (1991), «Medecine Moderne et Quête de Sens: la Maladie Signifiant Social», in Marc Augé; Claudine Herzlich (orgs.), Le Sens du Mal: Anthropologie, Histoire, Sociologie da la Maladie. Paris: Editions des archives contemporaines.

https://citeseerx.ist.psu.edu/viewdoc/download?doi=10.1.1.502.2431\&rep=rep1\&type=pdf

Hunt-Kennedy, Stefanie (2020), Between fitness and death: disability and slavery in the Caribbean. Urbana: University of Illinois Press.

Hutchison, Peggy; Alison Pedlar, Peter Dunn, John Lord, Sue Arai. Canadian Independent Living Centres:Impact on the Community. International Journal of Rehabilitation Research. 2000; 23(2): 61-74.

Jarrett, Tim (2018). Local replacements for the Independent Living Fund (ILF). House of Commons Library - Briefing Paper, Number 7788, 8 January 2018

Jornal Associação, 1996. "Acção de consciencialização sobre a deficiência”, n. 93 - Maio 1996, pág. 4.

Morris, Jenny 2003. Barriers to Independent Living: A scoping paper prepared for the Disability Rights Commission. Disponível em: https://citeseerx.ist.psu.edu/viewdoc/download?doi $=10.1 .1 .598 .4176 \&$ rep $=$ rep $1 \&$ type $=$ pdf

Morris, Jenny 2005. The implications for social care of the Disability Equality Duty A paper prepared for the Disability Rights Commission. Disponível em:

Oliver, Michael (1990), The politics of disablement : a sociological approach. New York: St. Martin's Press.

Oliver, Michael; Colin Barnes, 2012. The New Politics of Disability. Basingstoke, Palgrave Macmillan.

Pearson, Charlotte (2012), "Independent Living", in Alan Roulstone Nick Watson, Carol Thomas (org.), Routledge Handbook of Disability Studies. Abingdon: Routledge.Roulstone, Alan; Simon Prideaux 2012. Understanding Disability policy. Bristol: The Policy Press.

Santos, Boaventura de Sousa (1990), O Estado e a Sociedade em Portugal (1974-1988). Porto: Afrontamento.

Townsley, Ruth 2010. The Implementation of Policies Supporting Independent Living for Disabled People in Europe: Synthesis Report. Academic Network of European Disability experts (ANED) - VT/2007/005. Disponível em: https://d1wqtxts1xzle7.cloudfront.net/44706566/ ANED-Task_5_Independent_Living_Synthesis_Report_14.01.10-with-cover-page.pdf?Expires $=1620756613 \&$ Signature=EzdzPhUeG2ysFGJzhi 4CvHnSMG9pz05aNAq7iCxp5bBdKiH9Irb- 
Dy5lkY2og8YBdGxMIVStby-T-usi2t2lM3yC5MjAvvREPxUZeCHfoTzj-dh-U2bWKskgFgrb3u8ZUZwMUDergNB8rFzOwwtQR4ZXaqw54UleXQpHGp6S5kPf9FeJvTTai6w4aYJEov5mmFJyJl -fzT31Hy6sqDHuvCh4XwUWLBJP4KH 2RTwXgCFWEzqR-BiWnv g1Bbhgrmfab-9p5ztDW5yqh8v4TFkFlmCeHIwkQWcluoS7sREjOwTRcUFKee2giYaOx4hMPRYkaze oG k6qYQO8TjRxA_\&Key-Pair-Id=APKAJLOHF5GGSLRBV4ZA

White GW, Lloyd Simpson J, Gonda C, Ravesloot C, Coble Z. Moving from Independence to Interdependence: A Conceptual Model for Better Understanding Community Participation of Centers for Independent Living Consumers. Journal of Disability Policy Studies. 2010;20(4):233-240. doi:10.1177/1044207309350561

Recebido em: 27/07/2021

Aprovado em: 27/08/2021

\section{Como citar este artigo:}

FONTES, Fernando e MARTINS, Bruno Sena. Vida Independente para pessoas com deficiência: do individualismo à autodeterminação. Contemporânea - Revista de Sociologia da UFSCar, v. 11, n. 2, maio - agosto 2021, pp. 526-540. 